\title{
Boron Fertilizer Product and Concentration Influence Spray Water pH
}

\author{
Frank J. Peryea ${ }^{1}$ and \\ J ennifer M. L ageschulte ${ }^{2}$
}

\begin{abstract}
ADDITIONAL INDEX WORDS. mineral nutrition, micronutrient, pesticide, growth regulator, water quality, alkaline hydrolysis
\end{abstract}

\begin{abstract}
Summary. Farmers often mix fertilizers, pesticides and other agricultural chemicals together in a spray tank to allow applications of multiple products in a single spray. Because polyboratebased $\mathbf{B}$ fertilizers may increase solution $\mathrm{pH}$, adding $\mathrm{B}$ to tank-mixed sprays may impair the stability and efficacy of alkalinity-sensitive pesticides and growth regulators if an acidifier is not included. We conducted a labora tory experiment to determine the influence of $\mathbf{1 0}$ commercial B fertilizer sources in factorial combination with B concentrations ranging from 0 to $4 \mathrm{lb} /$ $100 \mathrm{gal}\left(4.8 \mathrm{~g} \cdot \mathrm{L}^{-1}\right)$ on solution $\mathrm{pH}$ values of distilled water and two natural waters. T wo boric acid-based compounds produced acidic reactions relative to background water $\mathrm{pH}$ at all tested B concentrations. Their pH responses were influenced by initial water composition. Seven B products produced moderately to strongly alkaline reactions at all but the highest $B$ concentration, regardless of the form of B (polyborate vs. boric acid) initially present in the formulated products. O ne polyborate product formulated with an acidifier showed intermediate $\mathrm{pH}$ behavior. The dependence of
\end{abstract}

\footnotetext{
Tree Fruit Research and Extension Center, Washington State U niversity, 1100 N orth Western Avenue, Wenatchee, WA 98801.

$M$ ention of a proprietary product does not constitute an endorsement or a recommendation for its use by Washington State U niv. This research was conducted under Project WN P0747, College of Agriculture and $\mathrm{H}$ ome E conomics, Washington State U niv., Pullman. Funding support was provided by the College and by theW ashington Tree Fruit Research Commission. The cost of publishing this paper was defrayed in part by the payment of page charges. U nder postal regulations, this paper therefore must be hereby marked advertise ment solely to indicate this fact.

${ }^{1}$ Associate soil scientist and associate horticulturist.

${ }^{2} \mathrm{Agricultural}$ research technologist II .
} 
solution $\mathrm{pH}$ on B rate of the polyborate-containing products was identical in all three waters. The maximum $\mathrm{pH}$ values generated by all products occurred in the $B$ concentration range $<0.1$ to $0.25 \mathrm{lb} / 100 \mathrm{gal}$ $\left(0.12\right.$ to $\left.0.3 \mathrm{~g}^{\cdot \mathrm{L}^{-1}}\right)$. Solution $\mathrm{pH}$ values declined with increasing B concentra tion above this range. The $\mathrm{pH}$ responses qualitatively conformed to known aqueous chemical behavior of $B$ and the product additives. The complexity of the interaction between initial water chemistry, B concentration, and B fertilizer product reinforces the need to measure the pH of Bamended spray water before adding pH -sensitive compounds.

A Ikaline hydrolysis of pesticides in high pH spray water can reduce the stability and efficacy of many pesticides ( $\mathrm{N}$ iessen, 1978; Seaman and Reidl, 1986). Pesticides and growth regulators sensitive to high $\mathrm{pH}$ include azinphos-methyl, parathion, carbaryl, dimethoate, and Promalin (Abbott Laboratory, Abbott Park, III.). $M$ any natural waters have $\mathrm{pH}$ values high enough to affect some pesticides. Acidifying chemicalsmustbeadded to reducepH in such waters or when al kalinity-generating chemicalsaretank-mixed with susceptible pesticides.

Boron deficiency is a common problem of agricultural crops that can be corrected or prevented by foliar application of small quantities of B-containing fertilizer. Boron products often are mixed with other products in the spray tank to allow multipleapplications of agricultural productsin asinglespray, thereby reducing cost of application.

O rthoboric acid wasthefirst B com- pound used for foliar sprays, starting about 1936 (Peryea, 1992). It was largely replaced about 1952 by sodium polyboratebased products which were as effective as boric acid in providing $B$ to plants but dissolved more quickly in spray water. Orthoboric acid does not behave as a simplemonoproticacid; rather, it formsan acid-base adduct with water and ionizesto release a single hydrogen ion (Keren and Bingham, 1985), causing a decline in solution $\mathrm{pH}$ in poorly buffered waters: $\mathrm{B}(\mathrm{OH})_{3}(\mathrm{~s})+\mathrm{H}_{2} \mathrm{O}(\mathrm{l})=\mathrm{B}(\mathrm{OH})_{4}^{-}(\mathrm{aq})+$ $\mathrm{H}+(\mathrm{aq})$

In contrast, sodium polyboratecompounds release hydroxyl ions upon hydrolysisand cause solution $\mathrm{pH}$ to increase (Colwell and Cummings, 1944). An alkaline reaction is not of consequence if the sodium polyborate-based product isto be applied as a single-product spray or tankmixed with other compounds not sensitive to alkalinity. Tank-mixing sodium polyborate-based productswith alkalinitysensitive compounds may chemically degrade the compounds and impair their effectiveness. Adding acidifiersto aqueous solutions of sodium polyborate-based products can neutralize the induced alkalinity but increase overall spray cost.

D evelopments in fertilizer formulation have greatly expanded the composition of available $B$ products used for spray applications. Some products contain B complexed with organic compounds claimed to enhance B phytoavailability. A recent advance is use of proprietary additives and processing techniques to enhance the rate of boric acid dissolution. $\mathrm{N}$ et changes in $\mathrm{pH}$ resulting from adding these $B$ spray products to spray water are not well-characterized. The current laboratory study examinesthe effect of $B$ spray product source and $\mathrm{B}$ concentration on spray water $\mathrm{pH}$.

\section{Materials and methods}

Reagent-grade orthoboric acid and 10 commercial B spray products were evaluated (Table1). Albion Liquid Boron, B-17, Borosol-10, M orBor-17, Solubor, and Solubor DF are specifically approved for use as fertilizersin organic farms in the state of Washington (Washington State D epartment of Agriculture, 2000).

Three water sources were used to prepare the B solutions: distilled water, Wenatchee canal water (WCW), and Tonasket well water (TWW). The WCW wascollected from theH ighlineirrigation canal which carrieswater diverted from the WenatcheeR ivernear $D$ ryden, Wash. The TWW was collected from a well on an orchard in Tonasket, Wash. Both natural water sources are used to prepare spray tank solutions in commercial tree fruit orchards. T able2 summarizestheconcentrations of selected inorganic constituents of thetwo waters. Both waterswerenaturallyalkaline. Estimated alkalinity was 12.3 times higher in the TWW than in the WCW, suggesting that the TWW had substantially greater buffering capacity against acidification. Both waters would be considered suitable as irrigation water except that use of TWW for overhead sprinkling likely would causeformation of limedepositson wetted plant parts (Ayers and Wescot, 1976).

In the laboratory, solutions containing $B$ concentration equivalent to $4 \mathrm{lb} /$ $100 \mathrm{gal}\left(4.8 \mathrm{~g} \cdot \mathrm{L}^{-1}\right)$ were prepared using each productand water combination. This $B$ concentration exceeds that likely to be used by commercial tree fruit growers (British ColumbiaM inistry of Agriculture

Table 1. B oron spray products evaluated in study.

\begin{tabular}{|c|c|c|c|c|c|}
\hline $\begin{array}{l}\text { Product } \\
\text { name }\end{array}$ & $\begin{array}{c}\text { Physical } \\
\text { state }^{z}\end{array}$ & $\begin{array}{c}\text { B } \\
\text { content } \\
(\%)\end{array}$ & $\begin{array}{l}\text { B } \\
\text { form }\end{array}$ & Additive & Manufacturer \\
\hline Albion Liquid Boron & $\mathrm{L}$ & 5.0 & $\mathrm{~N} a \mathrm{~B}$ & Amino acids & Albion Lab., Clearfield, U tah \\
\hline B-17 & $\mathrm{S}$ & 17.0 & BA & Surfactant & N utrient Technol., La H abra, Calif. \\
\hline Borosol-10 & $\mathrm{L}$ & 10.0 & BA & Ethanolamine & Clean Crop, Fremont, N ebr. \\
\hline $\mathrm{N}$-Boron & $\mathrm{L}$ & 5.4 & $\mathrm{BA}$ & U rea, polysaccharides & Plant H ealth Technol., Boise, I daho \\
\hline Solubor & $\mathrm{S}$ & 20.5 & $\mathrm{~N} a \mathrm{~B}$ & None & U.S. Borax, Los Angeles, Calif. \\
\hline Solubor DF & $\mathrm{S}$ & 17.4 & $\mathrm{NaB}$ & None & U.S. Borax, Los Angeles, Calif. \\
\hline SprayB or & $\mathrm{S}$ & 16.5 & $\mathrm{NaB}$ & Acidifier & Plaaskem, Gauteng, South Africa \\
\hline Tech-Spray Liquibor & $\mathrm{L}$ & 2.5 & $\mathrm{BA}, \mathrm{N}$ aB & Surfactant & N utrient Technol., D inuba, Calif. \\
\hline
\end{tabular}

${ }^{2} \mathrm{~S}=$ solid; $\mathrm{L}=$ liquid.

yPercent $B$ by weight.

${ }^{\mathrm{X}} \mathrm{B}=$ = boric acid, $\mathrm{N}$ aB $=$ sodium polyborates of varying composition. 
T able 2. C hemical characteristics of Wenatchee canal water (WC W) and T onasket well water (T WW ) used in study.

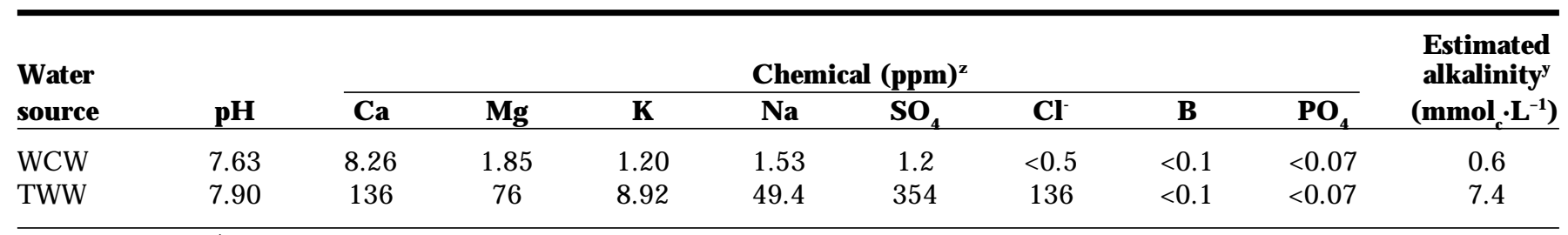

z1.0 ppm $=1.0 \mathrm{mg} \cdot \mathrm{L}^{-1}$.

ySum of $\mathrm{CO}_{3}{ }^{2-}$ and $\mathrm{HCO}_{3}{ }^{-}$, calculated as the difference between the summations of measured concentrations of cations and anions expressed in mmol $\mathrm{C}^{-L^{-1}}$ (meq $\mathrm{L}^{-1}$ ).

and Food, 1998; Smith, 2000). The pH values of these initial solutions were mea sured using a temperature-compensated combination glass electrode. The solutionswerethen diluted byadding aknown volume of the same water used to prepare the starting solutions. The diluted solutions were allowed to equilibrate and $\mathrm{pH}$ was again measured. This procedure was continued with increasing amounts of dilution to afinal $B$ concentration equivalent to $0.1 \mathrm{lb} / 100 \mathrm{gal}\left(0.12 \mathrm{~g} \cdot \mathrm{L}^{-1}\right)$, which is lower than that usually recommended asa maintenance rate for deciduous tree fruit orchards (e.g.; Smith, 2000; Stiles and Reid, 1991). Each B product-water combination was tested in duplicate.

\section{Results and discussion}

ThepH valueoftheB-freedistilled water was 5.65, as expected for pure water in thermochemical equilibrium with atmospheric $\mathrm{CO}_{2}$. The $\mathrm{pH}$ values of the experimental $\mathrm{B}$ solutions ranged from moderately acidic to strongly alkaline(Fig. 1). Therelative $\mathrm{pH}$ ranking of the products averaged over all concentrations was: reagent-grade boric acid $\leq \mathrm{B}-17<$ M orBor-17 < Spraybor < Greenleaf Boron < Albion Liquid Boron, Solubor D F, Liquibor < Solubor < $\mathrm{N}$-Boron < Borosol-10.

Solution $\mathrm{pH}$ values for a given concentration of the boric acid-based compounds tended to be higher in the order: distilled $<\mathrm{WCW}<\mathrm{TWW}$, consistent with the measured $\mathrm{pH}$ and estimated alkal inity of thethree waters. The sodium polyborate-based products and the $\mathrm{N}$-containing boric acid-based Borosol and $\mathrm{N}$-Boron showed similar responses in all three waters, suggesting that some component of the formulationswasbuffering solution $\mathrm{pH}$ at levels specific to the individual products.

Reagent-grade boric acid and B17, aboric acid-based product, decreased $\mathrm{pH}$ at all $\mathrm{B}$ concentrations, in reference to the background $\mathrm{pH}$, in all three waters. Although M orBor-17 also is a boric acid-based product, it increased $\mathrm{pH}$ in distilled water and decreased $\mathrm{pH}$ in the two natural waters. It generated slightly to substantially higher $\mathrm{pH}$ values than did its analog B-17, presumably because the surfactant in itsformulation has more alkaline properties than that used in B-17.

All of the remaining products caused solution $\mathrm{pH}$ to increase with product-specific $\mathrm{pH}$ maxima occurring in the $B$ concentration range of $<0.1$ to $0.25 \mathrm{lb} / 100 \mathrm{gal}$ ( $<0.12$ to $0.3 \mathrm{~g} \cdot \mathrm{L}^{-1}$ ). Solution $\mathrm{pH}$ declined with increasing $B$ concentration above the $\mathrm{pH}$ maxima. This behavior conforms to known B solution chemistry. Boron occurs principally as the uncharged $\mathrm{B}(\mathrm{OH})_{3}$ molecule and $\mathrm{B}(\mathrm{OH})_{4}^{-}$anion at $\mathrm{B}$ concentrations below about $0.23 \mathrm{lb} / 100 \mathrm{gal}$ (0.28 $\mathrm{g} \cdot \mathrm{L}^{-1}$ ) (Keren and Bingham, 1985). Athigher B concentrations, these monomeric speciesbegin to polymerize into polyborate molecules and release $\mathrm{H}^{+}$ions and water.

The $\mathrm{pH}$ values of several alkalinitygenerating $B$ product and water combinationsapproached or declined below B-free

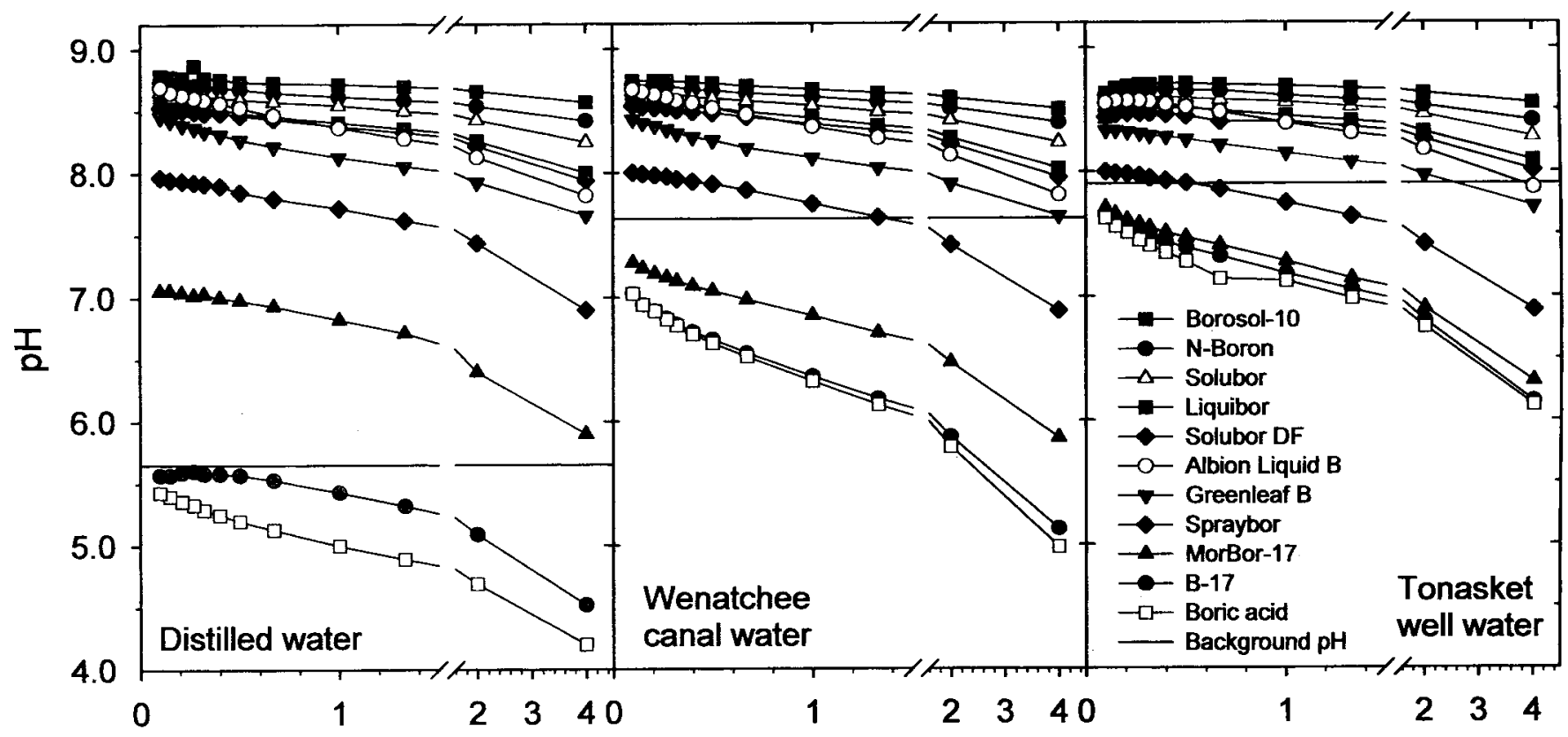

Product concentration (lb B/100 gal of water)

Fig. 1. Interaction of B fertilizer product, B rate and water source on spray solution $\mathrm{pH}$; $1 \mathrm{lb} / 100 \mathrm{gal}=1.2 \mathrm{~g} \cdot \mathrm{L}^{-1}$. 
water $\mathrm{pH}$ at the highest $\mathrm{B}$ concentrations (Spraybor in all three waters; Greenleaf Boron in WCW and TWW; and Albion Liquid Boron in TWW). Five products (Solubor, SoluborDF, Borosol, Liquibor, $\mathrm{N}$-Boron) caused $\mathrm{pH}$ to increase at all tested B concentrations.

The additivesin some of the $B$ products qualitatively explain the differential $\mathrm{pH}$ effects. Theacidifier incorporated into Spraybor was effective at partially neutralizing thepH increasecaused bypolyborate hydrolysis. The possible presence of residual processing acid in G reenleaf Boron makes it a less alkaline product than the polyborate-onlyproducts, asdoesthepresence of amino acids in Albion Liquid Boron. $\mathrm{H}$ ydrolysis of amino compounds and ureaand consequent release ofammonium likely accounts for the high $\mathrm{pH}$ values generated by the boric acid-based $\mathrm{N}$-Boron and Borosol-10. The small amount of sodium polyboratein theboric acid-dominated Liquibor appears to increase and maintain solution $\mathrm{pH}$ in the rangecharacteristic of thepolyborate-only products.

\section{Conclusions}

Of 10 tested products formulated for use in $B$ nutritional sprays, only the boric acid-based B-17 and M orBor-17 did not increase solution $\mathrm{pH}$ over background levels in natural waters; rather, they reduced $\mathrm{pH}$. For many spray waters, using these productsastheB source for tank-mixes would eliminate the requirement for adding an acidifier to counterbalance B product-induced alkalinity. In waters that are naturally alkaline and highly $\mathrm{pH}$-buffered, the acidity generated by boric acid-based products alone may be insufficient to reduce final solution $\mathrm{pH}$ to values low enough to preclude alkaline hydrolysis. Addition of an exogenous acidifier may still be required in such waters. It is possible that adding boric acid-based products to poorly buffered naturally acid waters could reduce $\mathrm{pH}$ to values low enough to influence the chemistry of acid-sensitivetank-mixed compounds, thereby requiring addition of an acidneutralizing agent. Diazinon is an example of a pesticide that degrades rapidly in low pH solutions (Bailey et al., 1996).

All of theremaining productscaused $\mathrm{pH}$ to increase, sometimessubstantially, at theB spray concentrationslikely to beused in agricultural settings, typically less than $1 \mathrm{lb} / 100 \mathrm{gal}\left(1.2 \mathrm{~g} \cdot \mathrm{L}^{-1}\right)$. Tank-mixing of these latter $B$ products with alkalin- ity-sensitive crop protection chemicals and growth regulators therefore would requireaddition of an acidifier to reduce solution $\mathrm{pH}$ to an acceptable level. Less acidifier may be required for Spraybor because it produced a smaller $\mathrm{pH}$ increase than did the other sodium polyborate-based products. The differencein $\mathrm{pH}$ performancebetween thesix most alkaline B products was small enough to be of little practical significance; hence, other properties, such as organic certification, handling characteristics, and cost may distinguish which of these product is best suited for a particular spray application.

\section{Literature cited}

Ayers, R.S., and D.W. Westcot. 1976. Water quality for agriculture. I rr. D rainage Paper 29. Food Agr. O rgan. U nited N ations, Rome, I taly.

Bailey, H .C., C. DiGiorgio, K. Kroll, J.L. M iller, D.E. H inton, and G. Starrett. 1996. D evelopment of procedures for identifying pesticide toxicity in ambient waters: Carbofuran, diazinon, chlorpyriphos. Environ. Toxicol. Chem. 15:837845.

British Columbia M inistry of Agriculture and Food. 1998. Tree fruit production guide for commercial growers, interior districts, 1998-99 edition. B.C. M in. Agr. Food, Victoria.

Colwell, W.E. and R.W. Cummings. 1944. Chemical and biological studies on aqueous solutions of boric acid and of calcium, sodium, and potassium metaborates. Soil Sci. 57:37-49.

Keren, R. and F.T. Bingham. 1985. Boron in water, soils, and plants, p. 229-276. In: B.A. Stewart (ed.). Advancesin soil science. SpringerVerlag, N ew York.

N iessen, H .J . 1978. Relationshipsbetween acidity/ alkalinity and pH hydrogen-ion concentration and their importance to pesticide specifications. Pesticide Sci. 9:603-609.

Peryea, F.J. 1992. H istory of boron research in apples, pears reviewed. Good Fruit Grower 43:26-29.

Seaman, A.J. and H. Riedl. 1986. Preventing decomposition of agricultural chemicals by alkaline hydrolysisin the spray tank. Cornell U niv. Food Life Sci. Bul. 118.

Smith, T.J. 2000. 2000 crop protection guide for tree fruits in Washington. Wash. State U niv. Bul. EB0419.

Stiles, W.C. and W.S. Reid. 1991. O rchard nutrition management. Cornell U niv. Coop. Ext. Info. Bul. 219.

Washington State D epartment of Agriculture. 2000. Brand names materials list. version 6. O rganic Food Progr., Wash. State D ept. Agr., Olympia. 